\title{
Motivational profiles and proactive career behaviors among the solo self-employed
}

Motivational profiles and career behaviors

Human Resource Studies, Tilburg School of Social and Behavioral Sciences, Tilburg University, Tilburg, The Netherlands

Silvia Rossetti

Utrecht University, Utrecht, The Netherlands and

Panteia, Zoetermeer, The Netherlands

Mattis van den Bergh

Department of Methodology, Tilburg School of Social and Behavioral Sciences, Tilburg University, Tilburg, The Netherlands and

Human Resource Studies, Tilburg School of Social and Behavioral Sciences, Tilburg University, Tilburg, The Netherlands, and

T.A.M. (Dorien) Kooij and Rob. F. Poell

Human Resource Studies, Tilburg School of Social and Behavioral Sciences, Tilburg University, Tilburg, The Netherlands

\begin{abstract}
Purpose - As the current "one size fits all" research approach is likely to be ineffective in identifying the conditions that promote the entrepreneurial career of the solo self-employed, this paper advances the current understanding of the heterogeneity among the solo self-employed.

Design/methodology/approach - A person-centered approach is used to identify groups among the solo self-employed based on their starting motives and to examine their engagement in proactive career behaviors. Findings - Using Latent Class Analysis (LCA), six groups displaying distinct motivational profiles are identified: (1) the pushed by necessity, (2) entrepreneurs by heart, (3) control-seekers, (4) occupationally-driven, (5) challenge-seekers and (6) the family business-driven. In line with the argument that starting motives affect behavior because they reflect the future work selves that individuals aim for, results show that solo selfemployed with distinct motivational profiles differ in their engagement in proactive career behaviors. For future research, it is recommended to examine the role of demographic characteristics in the engagement in proactive career behaviors.

Originality/value - Although starting motives among self-employed people have been studied frequently, this research applies an innovative methodological approach by using LCA. Hereby, a potentially more advanced configuration of starting motives is explored. Additionally, this study applies a career perspective
\end{abstract}

(C) Sjanne Marie Elyse van den Groenendaal, Silvia Rossetti, Mattis van den Bergh, T.A.M. (Dorien) Kooij and Rob. F. Poell. Published by Emerald Publishing Limited. This article is published under the Creative Commons Attribution (CC BY 4.0) licence. Anyone may reproduce, distribute, translate and create derivative works of this article (for both commercial and non-commercial purposes), subject to full attribution to the original publication and authors. The full terms of this licence may be seen at http:// creativecommons.org/licences/by/4.0/legalcode

This research did not receive any specific grant from funding agencies in the public, commercial, or not-for-profit sectors. All authors have agreed to the submission, and the article is not currently being considered for publication by any other journal.

Funding: This study was made possible by the research funding provided by Future of Work: an interdisciplinary project within the Faculty of Law, Economics, and Governance at Utrecht University and research funding provided by the Herbert Simon Research Institute within the Tilburg School of Social and Behavioral Sciences at Tilburg University.

Received 13 June 2020 Revised 11 December 2020 22 February 2021

Accepted 28 March 2021 
CDI

26,2

towards the domain of solo self-employment by exploring how solo self-employed with distinct motivational profiles differ in terms of managing their entrepreneurial careers.

Keywords Solo self-employed, Starting motive, Motivational profile, Proactive career behavior, Latent class analysis

Paper type Research paper

\section{0}

\section{Introduction}

The upward trend of the solo self-employed managing a business on their own account and risk without employing other people has triggered a lively interdisciplinary academic debate about the causes and implications of these rising numbers (Neneh, 2019). The increasing heterogeneity of this group has drawn far less attention until now (Van Stel and De Vries, 2015). Researchers in this field still often treat the solo self-employed as a homogeneous group (Burke, 2015). However, as noted by Burke (2015) and others, they have become a more and more heterogeneous group (e.g., Dawson and Henley, 2012; Jayawarna et al., 2011) in terms of demographics (Van Stel and De Vries, 2015), socio-economic characteristics (Van Stel and De Vries, 2015), and starting motives (Jayawarna et al., 2011). Therefore, the current "one size fits all" research approach is likely to be ineffective in identifying the conditions that promote the entrepreneurial career and well-being of the solo self-employed (Burke, 2015; Dawson and Henley, 2012). This paper aims to answer Burke's call (2015) for a better understanding of the heterogeneity among the solo self-employed.

Research on starting motives of the solo self-employed has a long history (e.g., Dawson and Henley, 2012; Dirven et al., 2017; Feldman and Bolino, 2000; Jayawarna et al., 2011), particularly contrasting opportunity and necessity starting motives using a so-called "push and pull approach" (e.g., Dawson and Henley, 2012; Zali et al., 2013). Here, necessity or "push" starting motives refer to a lack of opportunities for waged employment, while opportunity or "pull" starting motives represent the intrinsic need of profiting from specific benefits of solo self-employment, such as autonomy, independence and challenge.

Although this push and pull approach provides a stepping stone for understanding why individuals become solo self-employed and explains some heterogeneity in starting motives, it does not capture motives that are difficult to classify as either opportunity or necessity (Dawson and Henley, 2012), and assumes that entrepreneurship is based on one prevalent motive. However, entering solo self-employment is a complex decision where multiple and different motives may play a role (Segal et al., 2005). Therefore, we need an explorative approach to look for a more complete picture and examine the combination of motives that make up an individual's motivational profile to better understand the decision to become solo self-employed.

In the current literature, starting motives are mostly examined using a variable-centered approach, which assumes that the studied population is homogeneous (e.g., solo selfemployed with push starting motives engage less in proactive career behaviors compared to solo self-employed with pull starting motives; Hofmans et al., 2020) and only takes into account observed heterogeneity such as age, gender and occupation (Hofmans et al., 2020; Spurk et al., 2020). Although a variable-centered approach allows identifying relationships between variables at the group level and is an appropriate method to group items, it fails to show a potentially more advanced configuration of starting motives within individuals. Therefore, to respond to the call to examine the heterogeneity among the solo self-employed (Burke, 2015), we need an explorative person-centered approach that identifies specific configuration of starting motives within individuals that in concert shape behavior (Hofmans et al., 2020). A person-centered approach shows combinations of starting motives at the individual level, while taking into account unobserved heterogeneity (Hofmans et al., 2020; Howard et al., 2016; Spurk et al., 2020). 
Besides identifying groups of solo self-employed in terms of their starting motives, we explore how these groups differ in how they manage their entrepreneurial careers by looking at their engagement in proactive career behaviors. Unlike employees, the solo self-employed cannot rely on support from the organization, supervisors and colleagues (Engel et al., 2017; King, 2004) and thus are required to engage more in proactive career behaviors. Proactive career behaviors are self-initiated actions that help individuals anticipate opportunities and prevent risks along their careers (De Vos and Soens, 2008; Engel et al., 2017; King, 2004). Based on the concept of future work selves, we argue that the specific combination of starting motives will be related to differences in engagement in proactive career behaviors as an effort to actually become the desired future work selves (Carsrud and Brännback, 2011; Feldman and Bolino, 2000; Strauss et al., 2012). Future work self is defined as an individual's representation of himself or herself in the future that reflects his or her hopes and aspirations in relation to work (Strauss et al., 2012, p. 580), and thus affect behavior (Strauss et al., 2012).

In sum, our two research questions are (1) To what extent can groups of solo self-employed be identified based on their starting motives? (2) To what extent do these groups differ in their engagement in proactive career behaviors? Our intended contribution to the literature on careers of the solo self-employed is twofold. First, based on previous studies into starting motives that applied a variable-centered approach (Dawson and Henley, 2012), we provide an advanced theoretical and empirically validated configuration of starting motives to become solo self-employed (Spurk et al., 2020). We challenge Dawson and Henley's (2012) argument that there exists one predominant motive behind the choice of becoming solo self-employed and respond to their suggestion to develop questionnaire items to explore the ambiguity among starting motives. With the help of a person-centered methodology, however, we do not aim to develop new items for exploring starting motives but rather provide a realistic and fine-grained investigation of motivational profiles among the solo self-employed (Hofmans et al., 2020; Spurk et al., 2020). This person-centered approach enables us to identify a limited number of statistically and systematically different but internally homogeneous motivational profiles. Understanding the heterogeneity of motivational profiles of the solo self-employed provides opportunities for in-depth exploration within motivational profiles to examine factors that enhance the well-being and performance of these specific groups of solo selfemployed (Burke, 2015; Dawson and Henley, 2012). In addition, knowledge on such motivational profiles enables future scholars to compare factors that influence well-being and performance for different motivational profiles as well as cross-country comparison for the existence of such motivational profiles on the labor market.

Second, although motives are widely assumed to influence behavior (e.g., Howard et al., 2016), this is the first study explicitly investigating the link between motivational profiles and the more distal proactive career behaviors in which the solo self-employed engage after starting their business to shape their entrepreneurial careers. More particularly, we examine whether solo self-employed with a distinct combination of starting motives also differ in their engagement in proactive career behaviors. In order words, we investigate the idea that the motivational profile (i.e., the specific combination of starting motives) plays a key role in explaining proactive career behaviors of the solo self-employed. By applying a career perspective on the specific domain of solo self-employment using a person-centered methodology, this study advances our understanding of contemporary career development (Akkermans and Kubasch, 2017; Plomp et al., 2016; Spurk et al., 2020). More insight in engagement in proactive career behavior among the solo self-employed with different motivational profiles might help future scholars to understand and clarify entrepreneurial successes as engagement in proactive career behaviors is related to attaining positive career outcomes (De Vos et al., 2020; De Vos and Van der Heijden, 2015; King, 2004).
Motivational profiles and career behaviors 
CDI

26,2

312

\section{Theory on starting motives and proactive career behaviors}

Starting motives for solo self-employment

Traditionally, scholars have argued that people become solo self-employed to achieve economic gain (e.g., Schumpeter, 1934). In more recent literature, the increased heterogeneity of solo self-employed in terms of, for example, demographics (Van Stel and De Vries, 2015), has triggered researchers to look at other motives (e.g., Carsrud and Brännback, 2011; Jayawarna et al., 2011). In the late 1980s (Kirkwood, 2009), the academic debate was predominantly focused on the dichotomy between push (i.e., necessity) and pull motives (i.e., opportunity) (e.g., Dawson and Henley, 2012; Kirkwood, 2009). Although previous studies showed that the choice for solo self-employment may indeed be purely driven by either external constraints or by intrinsic needs, more recent research has found that many motives cannot be classified in the push-pull dichotomy and started questioning its general validity (e.g., Carsrud and Brännback, 2011; Dawson and Henley, 2012; Jayawarna et al., 2011).

In order to accommodate motives that fit the push nor the pull "box," the dichotomy has been re-conceptualized as a "volition" continuum with "push" and "pull" starting motives at the two extremes (Dawson and Henley, 2012). In this study, we use the push-pull continuum as a stepping stone for exploring a different configuration of starting motives to identify motivational profiles among the solo self-employed. Focusing on the same starting motives as those studied by Dawson and Henley (2012), we build further on the push-pull continuum in two ways. First, we not only explore whether we can identify motivational profiles that represent exclusively "push" or "pull" starting motives but also attempt to identify motivational profiles that capture combinations of starting motives that might be regarded as both "push" and "pull." An example can be found in the starting motives of the so called "lifestyle entrepreneurs" (e.g., Bredvold and Skålen, 2016; Dawson and Henley, 2012) to obtain a better balance in "economic, family, and social needs" and enhance life satisfaction (Bredvold and Skålen, 2016, p. 96). These motives could indicate the intrinsic need of profiting from solo self-employment opportunities in terms of autonomy and independence (i.e., pull), or conversely, these motives could indicate a reaction to external constraints to obtain these requirements in a job (i.e., push) (Carsrud and Brännback, 2011; Dawson and Henley, 2012; Van Gelderen and Jansen, 2006). Although similar in some regards, the pulled to solo selfemployed have a higher inner desire to manage a business (e.g., Dawson and Henley, 2012), while lifestyle entrepreneurs choose solo self-employment instrumentally to pursue a balance between economic, family and social needs (Bredvold and Skålen, 2016). As such, it is unclear whether lifestyle entrepreneurs' starting motives fall in between the two extremes of the push-pull continuum or represent pure push or pull motives or even a combination of both.

Second, we build further on the push-pull continuum by also identifying combinations of starting motives that are not unequivocally classifiable on the push-pull continuum. Consider individuals who became solo self-employed by their occupational choice (Dawson and Henley, 2012; Sorgner and Fritsch, 2013). They report an intrinsic need to perform a certain occupation, which, for external circumstances (e.g., market characteristics or legal requirements), is commonly performed in solo self-employment, such as lawyers, journalists or surgeons (Dawson and Henley, 2012; Sorgner and Fritsch, 2013). These people may be pulled toward solo self-employment if they were attracted not only by the occupation itself, but also by some aspects of performing their occupation of choice as solo self-employed (Sorgner and Fritisch, 2013). They may also be pushed towards solo selfemployment if they experience some aspects of solo self-employment as undesirable and would prefer to perform their occupation of choice as employee but cannot do so due to external constraints. Hence, whether occupation-related starting motives are linked to external circumstances (i.e., push) or intrinsic needs (i.e., pull) or a combination of both remains open for debate (Dawson and Henley, 2012). 
Therefore, by building on the push-pull continuum, we propose a more advanced configuration of starting motives representing different motivational profiles. Since the literature as outlined above has so far found four groups of solo self-employed based on their starting motives (Dawson and Henley, 2012), we expect to find at least those four distinct motivational profiles displaying starting motives related to (1) one or multiple external constraints (i.e., being pushed); (2) one or multiple intrinsic needs (i.e., being pulled); (3) lifestyle entrepreneurship; and (4) occupational choice. To examine these theoretical configuration, we propose a person-centered approach. With this approach, we place the individuals at the center and regard their starting motive(s) as the building block(s) of their whole motivational profile to become solo self-employed (Hofmans et al., 2020). Herewith, the person-centered approach shifts "the attention away from a focus on variables to a focus on individuals" (Hofmans et al., 2020, p. 2). Hence, a person-centered approach enables us to fully understand how we can group solo self-employed individuals based on their combinations of starting motives and create motivational profiles among them. As a result, a person-centered approach gives us a more realistic picture of the heterogeneity among the solo self-employed by identifying groups based on distinct motivational profiles (Hofmans et al., 2020; Spurk et al., 2020). To conclude, by applying a person-centered approach, we do not force starting motives on a push-pull continuum and allow motivational profiles to be shaped by combinations of starting motives.

\section{Proactive career behaviors}

As previously mentioned, engagement in proactive career behaviors refers to people proactively taking charge to anticipate opportunities and overcome risks along their careers (De Vos and Soens, 2008; King, 2004; Neneh, 2019; Pérez-López et al., 2016). In this study, we define proactive career behaviors as "the degree to which somebody is proactively developing his or her career as expressed by diverse career behaviours" (Hirschi et al., 2014, p. 577). From an entrepreneurship perspective, examining the proactiveness of solo self-employed workers is relevant, as it may help the solo self-employed to explore the environment, adapt to potential changes and outperform competitors (Blesa and Ripollés, 2003). More specifically, building on insights on proactive career behaviors from entrepreneurship as well as career literatures, the solo self-employed may challenge the status quo by engaging in different proactive career behaviors.

First, by engaging in skills and knowledge development (i.e., formal and on-the-job training), the solo self-employed invest in know-how and accumulate expertise in terms of knowledge, skills, and experiences which could be relevant at present as well as in later career stages (e.g., Engel et al., 2017; Kossek et al., 1998; Zahra et al., 1999). Second, through collaboration with other self-employed (i.e., long-term partnership), the solo self-employed actively share resources and as such attain work and wealth primarily through collaboration instead of competition (Freese and Van den Groenendaal, 2020; Magni and Mazzini, 2018). Third, networking (i.e., exchanging information and resources via social contacts, informally connecting with other solo selfemployed or developed via membership of interest groups) is a proactive way of creating access to social resources and seeking developmental feedback (Chiaburu et al., 2006; Jacobs et al., 2019), which seems particularly valuable for the solo self-employed without the support of an organizational career system (e.g., Engel et al., 2017; Jacobs et al., 2019). Fourth, the solo selfemployed may compensate for the risks of solo self-employment, such as financial insecurity (Burke et al., 2008), by actually having a second job as an employee, which refers to the proactive career behavior of engaging in hybrid employment. Hybrid employment is regarded as a way in which the solo self-employed "exercise agency over their working lives when facing an increased level of insecurity" (Murgia and Pulignano, 2019, pp. 2-3). Finally, the solo selfemployed could proactively invest in job mobility by undertaking actions to find a job in
Motivational profiles and career behaviors

313 
CDI

26,2

314

employment (Chiaburu et al., 2006; Kossek et al., 1998), which may entail an attempt to exit solo self-employment (Wennberg et al., 2010).

In the context of solo self-employment, motives not only influence the start of the business but also drive subsequent "behaviors where the goal is to survive, to succeed, and to avoid failure" in their careers (Carsrud and Brännback, 2011, p. 11). The extent to which the solo self-employed desire to survive, succeed and avoid failure in solo self-employment depends on how they regard their "future work selves" (Strauss et al., 2012). Strauss et al. (2012) defined the concept of "future work selves" as "representations of the self in the future that encapsulate individually significant hopes and aspirations in relation to work" (p. 581). In other words, it refers to the person the individual wants to become in the future in the context of his or her work (Strauss et al., 2012). With regard to the solo self-employed, we argue that the starting motives reflect the future work selves that individuals aim for (Feldman and Bolino, 2000). For example, individuals who have lifestyle-related starting motives will picture their future work self as a solo self-employed balancing economic, family and social needs (Bredvold and Skålen, 2016).

Individuals have been found to engage in proactive career behaviors helping them to become their "future work selves" (Strauss et al., 2012). Since future work selves are reflected in starting motives (Feldman and Bolino, 2000), we argue that starting motives may affect the engagement in proactive career behaviors of the solo self-employed. For example, we would expect lifestyle entrepreneurs to engage in collaboration with other self-employed to be able to be flexible and balance business and private needs. With regard to the pushed solo selfemployed, we would expected a higher engagement in proactive career behaviors related to (seeking) hybrid employment opportunities or exiting solo self-employment to obtain working conditions that were similar to their previous job in employment. We therefore expect groups of solo self-employed with distinctive motivational profiles to differ in their engagement in proactive career behaviors.

\section{Methods}

Sample

We examined our research questions using cross-sectional data drawn from the 2015 Dutch Self-employed Working Conditions Survey (conducted by CBS and TNO, $N=4,796$; Janssen et al., 2015). The Dutch Self-employed Working Conditions Survey is a representative sample of self-employed, including solo self-employed and self-employed with personnel. The Dutch Self-employed Working Conditions Survey items are based on a pre-existing questionnaire, called STREAM (Study on Transitions in Employment, Ability and Motivation) (Janssen et al., 2015). The theoretical foundation of the STREAM questionnaire is the AMO model (ability, motives, and opportunities), which serves as framework to investigate relevant determinants of labor market transitions (Appelbaum et al., 2000). The overall sample of selfemployed is drawn from the population of self-employed workers that in 2013 applied for income return tax, that in mid-November 2014 were part of a household registered at a Dutch address, and were at least 15 years old on the 1st of January 2015 (Dirven et al., 2017). The data collection was conducted at the beginning of 2015 by means of an Internet questionnaire.

In our sample, we included only the solo self-employed, consisting of 3,602 respondents. The majority was male (approximately 60\%), highly educated (finished tertiary education) (about $46 \%$; as opposed to middle and lower education) and older than 45 years. Most solo self-employed in the sample were professionals (41.44\%), service and sales workers $(14.31 \%)$, craft and related trade workers $(14.14 \%)$, and technicians and associates $(13.92 \%)$, and they worked mainly in industries such as business services (30.51\%), culture/recreation (12.13\%), and trade $(10.66 \%)$. See Table 1 in the Electronic Supplementary Material for the descriptive statistics. 
Items

I was looking for a new challenge

I joined in a family business

I always wanted to work as a solo self-employed

I wanted to combine work and private life better

I wanted to decide myself how long and when I work

I did not want to work for a boss anymore

My occupation is mostly performed in self-employment

I could not find a suitable job (in salaried employment)

I could make more money as a self-employed

I was fired or my contract was not extended

My employer wanted me to work as a self-employed

In my previous job the work atmosphere was not good

Others, namely... (was not included in the analysis)
Abbreviation of item in Figure 1

"Challenge"

"Family business"

"Always wanted"

"Work and private"

"Autonomy"

"No boss"

"Occupation"

"No suitable job"

"More money"

"Fired"

"Employer"

"Bad atmosphere"

"Others"
Motivational profiles and career

behaviors

315

Table 1.

Overview of item measuring starting motives

\section{Measurements}

Starting motives were measured by asking respondents to provide a "Yes/No" answer to 12 possible reasons for becoming solo self-employed reflecting a wide range of starting motives (including intrinsic needs, external constrains, and instrumental motives) (see Table 1). The items to measure the starting motives were selected based on answers in previously conducted Dutch Self-employed Working Conditions Survey (e.g., 2012 Dutch Self-employed Working Conditions Survey conducted by CBS and TNO; Ybema et al., 2012). The 12 motives presented to the respondents were based on the Self-Determination Theory (Ryan and Deci, 2000). These 12 motives were also used in previous studies such as Dawson and Henley (2012) and Dirven et al. (2017). In the case of multiple affirmative answers, no additional information was provided about the relative importance of the various motives, which were then considered as equally relevant in promoting the choice of starting a business. The option of multiple affirmative answers to motive items allowed for the individual choice of starting a business to be a complex endeavor, triggered by more than one (and possibly conflicting) motives.

Proactive career behaviors were operationalized as follows. Skills and knowledge development was a dichotomous variable measured with the question "have you attended at least one of the following activities in the last 12 months: training or instructions on the work floor, 1-5 days course or training, more than five days course or training, trade fairs, conferences, or seminars, meeting with suppliers or trade associations" $(1=$ yes) (e.g., see measurements of Barron et al, 1997). Collaboration with other self-employed was a dichotomous variable measured with the question "do you run your business with a fellow entrepreneur" (1 = yes) (e.g., see Halal, 2001). As we included only solo self-employed workers in our sample, we could clearly distinguish long-term collaboration from employing others. Networking was measured using two separate variables. The first variable was measured with the question "do you agree to the statement: In my work I look for people from whom I can learn" (response scale: 1 = completely disagree to 4 = completely agree) (e.g., see measurements of Jacobs et al, 2019; Strauss et al., 2012). The second variable was measured with the question "are you a member of a trade association or an interest group" $(1$ = yes). Seeking a job in employment was measured using two separate dichotomous variables $(1=$ yes). The first variable was measured with the question "have you considered finding a (new) job in employment in the past year." The second variable was measured with the question "have you actually taken actions to get a job in employment in the past year." Engaging in hybrid employment was measured with a dichotomous variable that asked respondents to report whether they were also employed as employees at the time of filling in the questionnaire. 
CDI

26,2

316
Latent Class Analysis

In order to identify different groups of individuals based on their starting motives, we applied Latent Class Analysis (LCA). LCA is an exploratory method, as "similar to what happens in exploratory factor analysis, in person-centered methods the relations between the profiles and indicators are typically freely estimated" (Hofmans et al., 2020, p. 3). LCA identifies distinct groups by comparing latent class models. Let $y_{i j}$ denote the responses of individual $i$ on the $j$ th categorical variable and $y_{i}$ the responses of individual $i$ on the full set $J$ variables, $X$ denotes the discrete latent class variable, $k$ denotes a particular latent class, and $K$ the number of latent classes. A LC model is specified for $P\left(y_{i}\right)$ as follows:

$$
P\left(y_{i}\right)=\sum_{k=1}^{K} P(X=K) \prod_{j=1}^{J} P\left(y_{i j} \mid X=K\right) .
$$

Here, the probability of belonging to class $k$ is represented by $P(X=k)$ and the probability of a certain response to item $j$ conditional on belonging to class $k$ is represented by $P\left(y_{i j} \mid X=k\right)$. The product of the class-specific response probabilities of the $J$ variables follows from the assumption of local independence. The model parameters are usually estimated by maximizing the likelihood through the EM algorithm (Dempster et al., 1977). All models in this paper were estimated with Latent GOLD 5.1 (Vermunt and Magidson, 2013). In line with most studies, we used the BIC (Bayesian information criterion) to decide on the number of groups (Nylund et al., 2007). As Nylund et al. (2007) explain, the BIC is a good indicator for "class enumeration over the rest" and "the adjusted BIC is superior to other IC statistics" (p. 537).

The external variables (i.e., demographic and socio-economic characteristics and proactive career behaviors) were related to the latent classes with the Latent Class "threestep approach". This provides unbiased estimates of the relationship between the assessed class memberships and socio-economic demographics and proactive career behaviors (Bakk et al., 2013; Vermunt, 2010). This allows to identify characteristics of individuals in the different motivational groups.

\section{Results}

In our analysis, we not only identified groups displaying different motivational profiles based on the starting motives presented above but also calculated their correlations with demographic and socio-economic characteristics: gender $(1=$ female), education level ( 1 = low, 2 = medium 3 = high), age (continuous variable), occupation and industry (both categorical variables). See Table 1 and an elaboration on the findings on demographic and socio-economic characteristics in the Supplementary Material.

\section{Groups of solo self-employed based on their motivational profiles}

We identified combinations of motives within individuals using LCA. Based on the lowest BIC that resulted from the LCA, we chose the 6-class model (see Table 2). We thus identified six groups of solo self-employed based on their different motivational profiles (Figure 1). Differences between the percentages in Figure 1 and the 3-step analysis presented in the text below are due to missing values on the variables for the 3-step analysis.

The distribution of the number of starting motives provided by each respondent (see Table 3) shows that becoming solo self-employed is not simply driven by one starting motive for the majority of our sample $(51.67 \%)$. About one-fifth of respondents indicated two starting motives $(19.91 \%)$, and about one-third of respondents reported even greater complexity by selecting either three $(16.41 \%)$ or more than three starting motives $(15.35 \%)$.

The first group is the largest and represented $27.80 \%$ of the sample. It is predominantly characterized by the starting motive related to looking for a new challenge ("challenge"). Also, 
but less relevant were motives concerning the benefit of choosing one's working schedule ("autonomy"), of being one's own boss ("no boss"), and balancing work and private life ("work and private"). In other words, for this group, looking for a new challenge was the most common starting motive. In addition, this need for a new challenge was often combined with the need for choosing one's working schedule, being one's own boss and balancing work and private life. Therefore, we defined this group as the challenge-seekers. See Figure 1 in the Supplementary Material for the overview of demographics and socio-economic characteristics of the challenge-seekers.
Motivational profiles and career behaviors

\begin{tabular}{|c|c|c|c|c|c|c|c|}
\hline 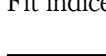 & LL & BIC(LL) & Npar & $L^{2}$ & df & $p$-value & Class.Err. \\
\hline 1-Group & -18002.7 & 36103.56 & 12 & 3457.143 & 3,585 & 0.94 & 0 \\
\hline 2-Group & -17356.1 & 34916.84 & 25 & 2163.982 & 3,572 & 1 & 0.1131 \\
\hline 3-Group & -17152.9 & 34616.93 & 38 & 1757.626 & 3,559 & 1 & 0.1011 \\
\hline 4-Group & -17051.4 & 34520.28 & 51 & 1554.537 & 3,546 & 1 & 0.1869 \\
\hline 5-Group & -16959.6 & 34443.19 & 64 & 1371.001 & 3,533 & 1 & 0.2119 \\
\hline 6-Group & -16900.8 & 34431.99 & 77 & 1253.357 & 3,520 & 1 & 0.2113 \\
\hline 7-Group & -16850.1 & 34437.2 & 90 & 1152.129 & 3,507 & 1 & 0.2386 \\
\hline 8-Group & -16807.4 & 34458.19 & 103 & 1066.678 & 3,494 & 1 & 0.2485 \\
\hline
\end{tabular}

Table 2.

Overview of profiles found

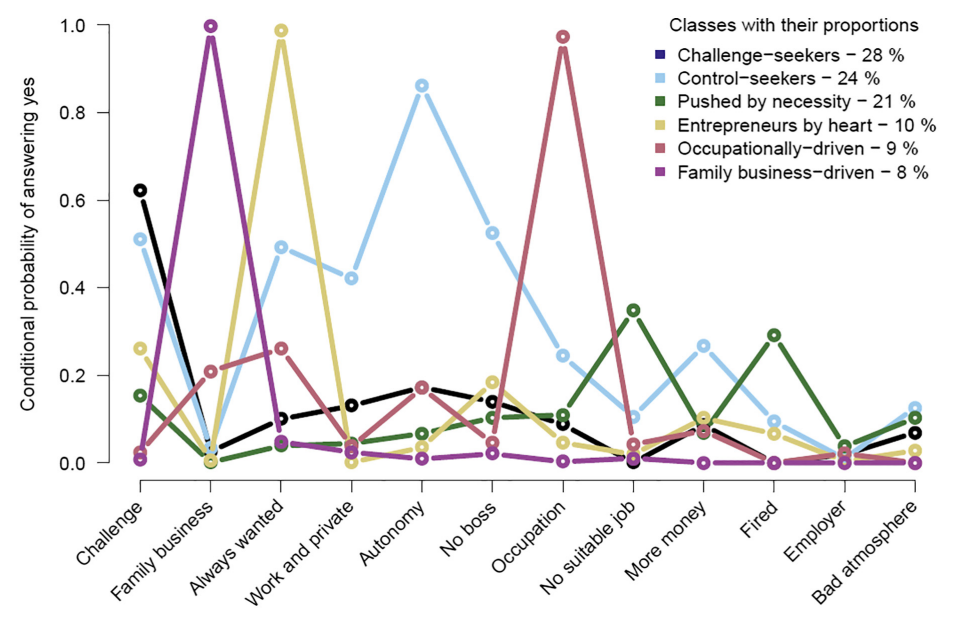

Figure 1.

Conditional probabilities of answering yes to the twelve items across the six motivational profiles [1]

\begin{tabular}{lcr}
\hline Number of motives indicated & Frequencies & $\%$ \\
\hline 0 motives & 264 & 7.33 \\
1 motive & 1,477 & 41 \\
2 motives & 717 & 19.91 \\
3 motives & 591 & 16.41 \\
$>3$ motives & 553 & 15.35
\end{tabular}

Table 3.

Frequencies of how many motives are indicated 
CDI

26,2

318

The second group included $26.12 \%$ of the sample and is dominated by the autonomy to decide one's working schedule ("autonomy"), followed by the desire not to work for a boss anymore (i.e., item "no boss"). Also relevant were starting motives associated with finding a new challenge ("challenge"), the desire of working solo self-employed ("always wanted") and the ability to combine work and private life better ("work and private"). Since the majority of the prevalent starting motives characterizing this group emphasized the desire for autonomy and control, we denoted this group as the control-seekers. See Figure 2 in the Supplementary Material for the overview of demographics and socio-economic characteristics of the controlseekers.

Also very pronounced was the group of solo self-employed reporting external constraints (21.65\% of the sample), which included a lack of alternative employment opportunities ("no suitable job") and being fired by the (former) employer or reaching the end of a contract ("fired"). Since none of these items expressed a genuine volition of respondents to become solo self-employed, the profile is defined as solo self-employment pushed by necessity. See Figure 3 in the Supplementary Material for the overview of demographics and socio-economic characteristics of the pushed by necessity.

The remaining three groups were more limited in size. The fourth group (9.93\%) indicated that working self-employed has always been a preferred employment form ("always wanted"), and somewhat relevant were the search for a challenge ("challenge") and being one's own boss ("no boss"). Since the preference for working as solo self-employed was dominant and the other motives were in line with the most typical entrepreneurial values, this group is named entrepreneurs by heart. See Figure 4 in the Supplementary Material for the overview of demographics and socio-economic characteristics of the entrepreneurs by heart.

The fifth group $(8.72 \%)$ was dominated by individuals that chose to become solo selfemployed because this was the way in which their occupation is normally performed ("occupation"). Also, the desire of working solo self-employed ("always wanted") and deciding one's own working schedule ("autonomy"), as well as the involvement in a family business ("family business") seemed to be important starting motives for this group. Here, becoming solo self-employed was mainly a consequence of choosing a certain occupational career, hence this profile is labeled occupationally-driven solo self-employment. See Figure 5 in the Supplementary Material for the overview of demographics and socio-economic characteristics of the occupationally-driven.

Finally, the sixth group $(7.67 \%)$ represented almost exclusively respondents that got involved in a family business ("family business") and is labeled family business-driven solo self-employment. See Figure 6 in the Supplementary Material for the overview of demographics and socio-economic characteristics of the family business-driven. Based on the findings, six groups displaying different motivational profiles to become solo selfemployed were found. See Table 2 in the Supplementary Material for an overview of significant demographic and socio-economic characteristics of the six groups.

\section{Groups of solo self-employed and engagement in proactive career behaviors}

Overall, some proactive career behaviors were more common than others. Engaging in skills and knowledge development and seeking people to learn from (i.e., networking) were frequent behaviors, shown by the majority of each group. Conversely, the solo self-employed engaged less in collaboration with other self-employed and hybrid employment ( $20 \%$ or less). The extent to which groups with distinct motivational profiles engaged in proactive career behaviors is represented in Figures 2-7. A summary of significant differences between the groups is presented in Table 4 . 


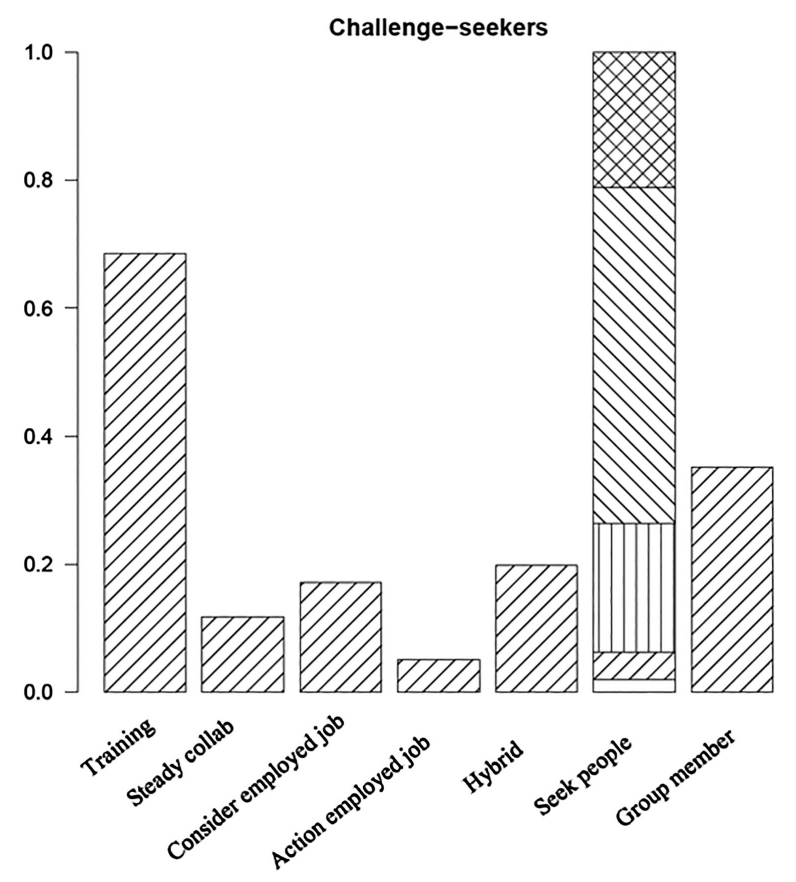

Motivational profiles and career behaviors

Figure 2. Behaviors of challenge-seekers

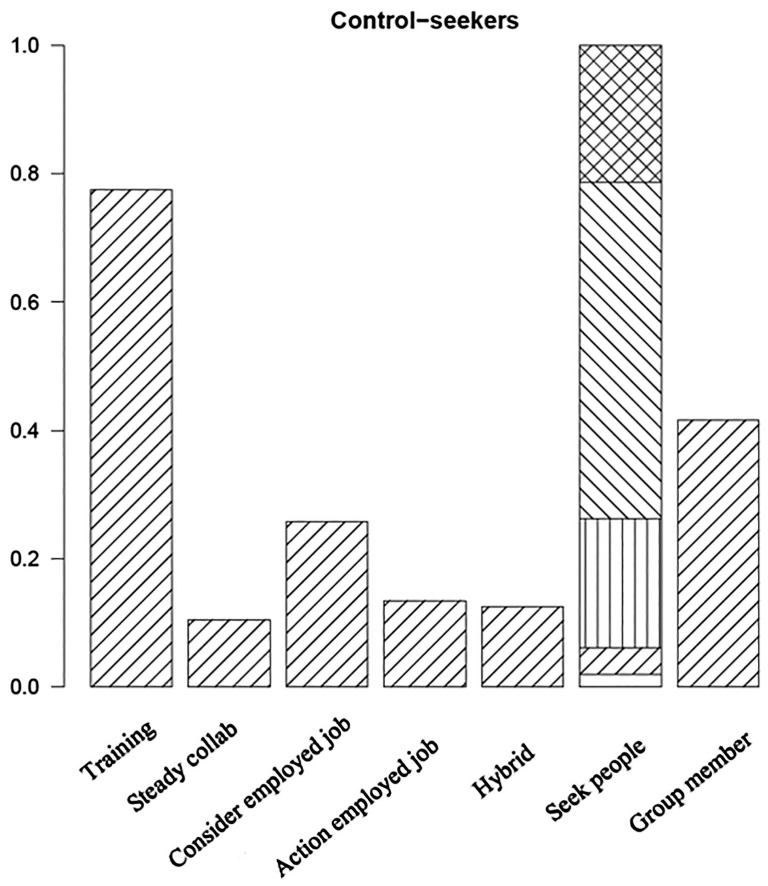

Figure 3.

Behaviors of controlseekers 
CDI

26,2

320

Figure 4.

Behaviors of pushed by necessity
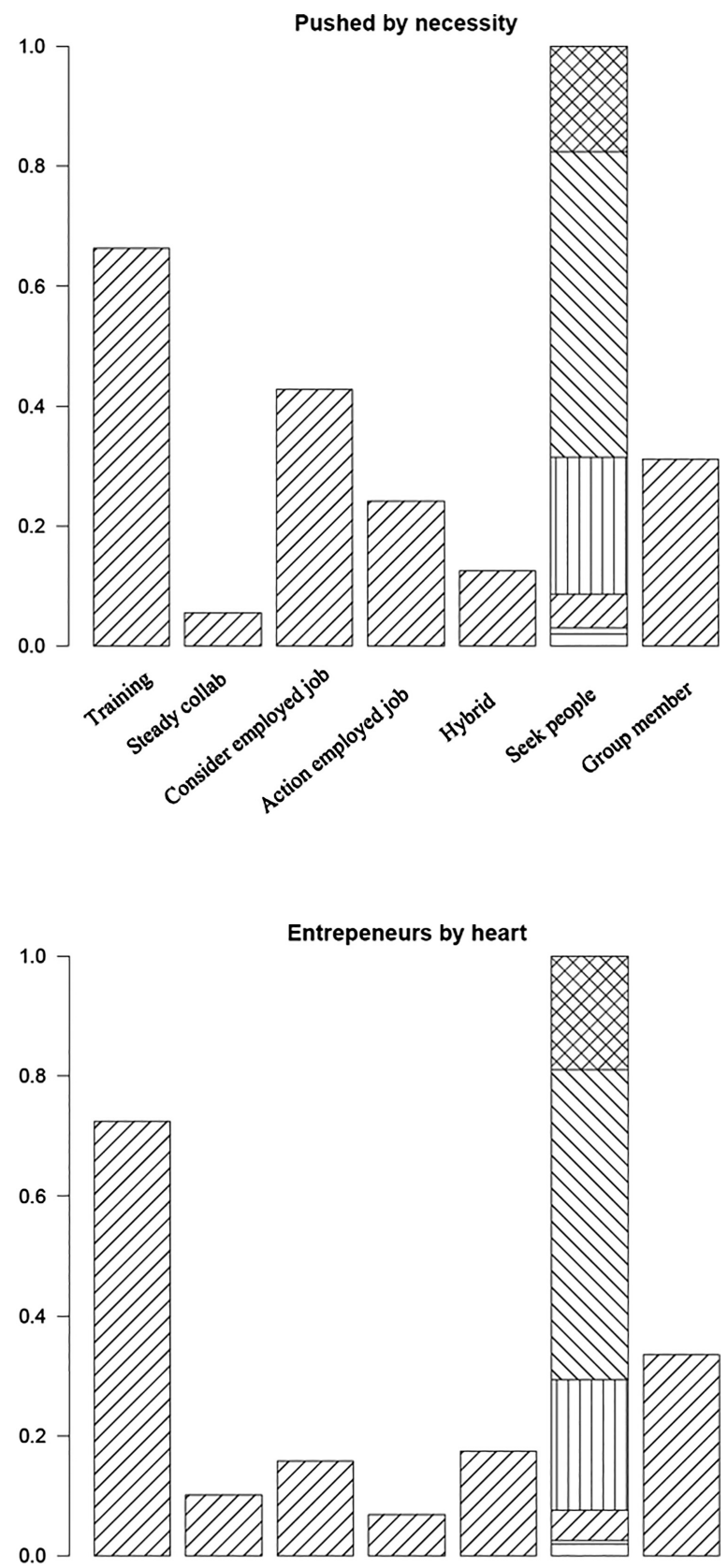

Figure 5.

Behaviors of

entrepreneurs by heart

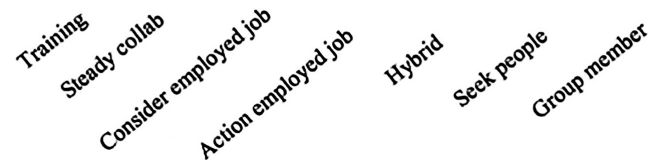




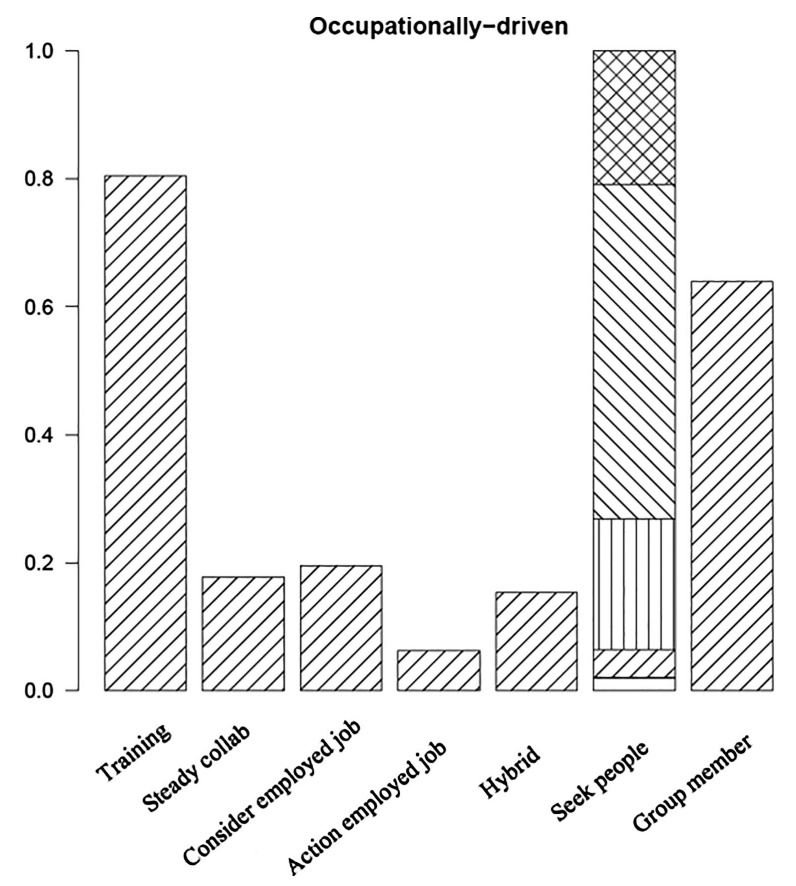

Motivational profiles and career behaviors

Figure 6. Behaviors of occupationally-driven

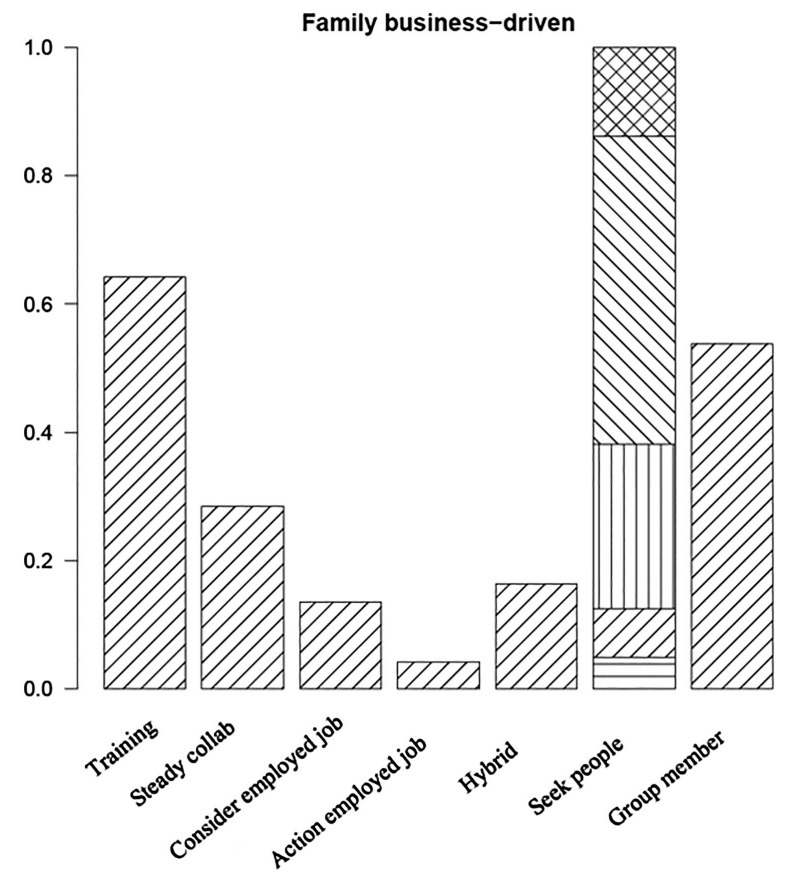

Figure 7. Behaviors of family business-driven 
CDI

26,2

Proactive behavior

Cross-groups significant difference patterns

Seeking opportunities to proactively develop skills and knowledge

(1) Training

$631(4)<(4) 25$

Collaboration with fellow solo self-employed workers

(1) Steady business collaboration

$3(4)<(4) 21<5<6$

Networking

(1) Seek people to learn from

(2) Membership of a trade association or an interest group

$6<3(451)<(451) 2$

$341<2<65$

Seeking a job in employment

(1) Considered seeking a job in employment

(2) Undertook actions to get a job in employment

$641(5)<(5) 2<3$

$6154<2<3$

Engaging in hybrid employment opportunities

(1) Employed as employee

No-sign. Differences

Note(s): 1- Challenge-seekers

Table 4.

2- Control-seekers

Summary of cross-

3- Pushed by necessity

group significant

4- Entrepreneurs by heart

differences in proactive 5-Occupationally-driven

behaviors [2]

6- Family business-driven

We expected that groups of solo self-employed displaying different motivational profiles would differ in the extent to which they engage in proactive career behaviors. A Wald chisquare test is conducted to examine whether engagement in proactive career behaviors significantly differs across the motivational profiles (i.e., latent classes) in terms of the mean differences. A non-significant Wald statistic $(\phi$-value $\geq 0.05)$ indicates that we cannot reject the null hypothesis that the covariates (proactive career behaviors) do not differ between the motivational profiles. A significant Wald statistic $(\phi$-value $\leq 0.05)$ indicates conversely that the null hypothesis can be rejected and allows us to state that there is a significant difference with regard to engagement in proactive career behavior across groups of solo self-employed with a different motivational profile.

Our results showed only partial support for this expectation. In contrast, no significant cross-group differences were found in the likelihood of engaging in actual hybrid employment. Support for our expectation was found for steady collaboration with other self-employed, for which we found four significantly different levels of engagement. First, the highest engagement in collaborations was found among the family business-driven group $(29 \%)(\mathrm{W}(1) \leq 38.93 p<0.05)$, which was followed by the occupationally driven $(18 \%)$ $(\mathrm{W}(1) \leq 5.64 p<0.05)$ representing the second highest engagement. Third, control-seekers engaged less in collaboration than the occupationally-driven $(\mathrm{W}(1) \leq 6.06 p<0.05)$. In between these two levels, the challenge-seekers did not engage in collaboration differently from the occupationally-driven and the control-seekers. Fourth, the pushed by necessity self-employed showed the lowest engagement in collaboration $(10 \%)(\mathrm{W}(1) \leq 38.93 p<0.05)$. Finally, the engagement of entrepreneurs by heart was not significantly different from pushed by necessity and from challenge-seekers and control-seekers.

Fewer significant differences were found for networking behaviors, since estimates of both seeking people to learn from and membership to a branch organization or an interest group showed two significant cross-group differences. One significant difference concerned the control-seekers, who were found to be more engaged in seeking people to learn from than the pushed by necessity $(\mathrm{W}(1) \leq 4.57 p<0.05)$. In between, we found that the engagement of 
entrepreneurs by heart, occupationally-driven and challenge-seekers was also high, but not significantly different from either control-seekers or pushed by necessity. The second significant difference depicted the family business-driven as the least likely to seek people to learn from $(\mathrm{W}(1) \leq 14.28 p<0.05)$.

Results concerning the second networking behavior (i.e., membership to a branch organization or an interest group) showed a different cross-groups pattern of engagement. Engagement in this behavior was the highest among the occupationally- and the family business-driven $(\mathrm{W}(1) \leq 45.21 p<0.05)$, was lower among the control-seekers $(\mathrm{W}(1) \leq 23.58$ $p<0.05$ ), and was lowest among and the pushed by necessity (W(1) $\leq 45.21 p<0.05)$. The engagement of challenge-seekers and entrepreneurs by heart was found not to differ significantly from the pushed by necessity and the challenge-seekers.

Skills and knowledge development was on average a frequent proactive career behavior for all groups. Here, only one significant difference showed that occupationally-driven and control-seekers were more likely to attend a training activity than challenge-seekers, pushed by necessity and family business-driven solo self-employed (W(1) $\leq 14.09 p<0.05)$. In between, the training attendance of entrepreneurs by heart was not significantly different from the attendance of the other groups.

Finally, two significant cross-group differences were found for seeking a (new) job in employment. Seeking a job in employment was most frequent among the pushed by necessity group $(42.78 \%-\mathrm{W}(1) \leq 40.7 p<0.05)$, less frequent among the control-seekers (W(1) $\leq 30.08$ $p<0.05)$, and least frequent among the entrepreneurs by heart, occupationally-driven, challenge-seekers, and family business-driven groups $(\mathrm{W}(1) \leq 39.04 p<0.05)$. Undertaking action to get a job showed a similar cross-group pattern (respectively $\mathrm{W}(1) \leq 24.2 p<0.05$; $\mathrm{W}(1) \leq 18.53 p<0.05$; and $\mathrm{W}(1) \leq 24.2 p<0.05)$. The only difference concerned the occupationally-driven. Although being less likely to consider seeking a job as employee, compared to the control-seekers, occupationally-driven did not have less propensity than the control-seekers to undertake actions to get a (new) job in employment once they had the intention to do so.

\section{Contributions and discussion}

Our first contribution lies in using a person-centered approach to explore motivational profiles among the solo self-employed and examine how motivational profiles are related to engagement in proactive career behaviors. In vocational research, the main focus has been on studying relationships between variables across individuals (Hofmans et al., 2020). As a result, the application of person-centered approaches, such as LCA, is still in an early development stage (Spurk et al., 2020). As we used a person-centered approach, we attempted to move the field of vocational research forward and encourage career scholars' interest in examining individuals and their career choices and behaviors by means of person-centered approaches.

Second, based on previously studied starting motives (e.g., Dawson and Henley, 2012; Dirven et al., 2017), we identified six motivational profiles among the solo self-employed. While identifying these motivational profiles, we noticed the importance of looking beyond the "push-pull" dichotomy in terms of single motives. The distribution of the number of starting motives provided by each respondent showed that becoming solo self-employed is not simply driven by one starting motive for the majority of our sample $(51.67 \%)$. This finding contradicts the results of Dawson and Henley (2012), who indicated that the big majority of their sample espoused a single motive.

Furthermore, our results provide valuable insights into the different motivational profiles. Previous empirical studies had captured four motivational profiles that displayed starting motives related to (1) one or multiple constraints, (2) one or multiple intrinsic needs, (3) 
CDI

26,2

lifestyle entrepreneurship, and (4) occupational choice. By using a person-centered approach, we identified motivational profiles representing necessity and opportunity starting motives (i.e., entrepreneurs by heart and pushed by necessity). Moreover, we found motivational profiles related to occupational choice (i.e., occupationally-driven) and the lifestyle entrepreneurship (i.e., control-seekers). More specifically, lifestyle entrepreneurs are individuals who became solo self-employed to realize a specific lifestyle that enabled them to balance "economic, family and social needs" (Bredvold and Skålen, 2016, p. 96). Comparing these characteristics with the starting motives indicated by the control-seekers, similarities are found with regard to their need for autonomy to decide one's working schedule, the desire not to work for a boss anymore, and the ability to combine work and private life better.

In addition to these four motivational profiles, we identified two additional motivational profiles (i.e., challenge-seekers and family business-driven). Hence, we were able to show the added value of the person-centered methodological approach. Therefore, concerning Dawson and Henley's (2012) call for developing questionnaire items to explore the ambiguity among starting motives, we argue that our theoretical and methodological approach surpasses the need for developing new items as the person-centered approach tackles the ambiguity as well.

Besides the entrepreneurs by heart and pushed by necessity profiles, two of our motivational profiles identified are in line with previous literature on lifestyle entrepreneurs (i.e., controlseekers) (Bredvold and Skålen, 2016), and solo self-employment driven by occupational choice (i.e., occupational choice) (Dawson and Henley, 2012; Sorgner and Fritsch, 2013). The challengeseekers and family business-driven had not been identified as specific groups of solo selfemployed yet. Previous studies had already found that looking for a new challenge is one of the most prevalent reasons to become solo self-employed (e.g., Dawson and Henley, 2012; Jayawarna et al., 2011). The present study not only confirms the search for a new challenge as a motivational profile but also shows that the search for a new challenge represents the predominant starting motive of the largest group among the solo self-employed in our sample. From this finding we conclude that looking for a new challenge in solo selfemployment is a distinct motivational profile. With regard to the family business-driven, previous studies had neglected family business owners under the assumption that they were not solo self-employed, as they are often characterized by the fact that multiple family members are working in the business. However, our study shows that examining the solo selfemployed who joined a family business is relevant, as $8 \%$ of the sample was family businessdriven at the moment of becoming solo self-employed and could therefore be identified as belonging to a distinct motivational profile.

The third contribution of this study relates to the link between motivational profiles and engagement in proactive career behaviors. The findings showed a number of significant differences in the extent to which groups of solo self-employed engage in proactive career behaviors. Therefore, our findings do resonate to some extent with our argument that starting motives relate to engagement in proactive career behaviors (Carsrud and Brännback, 2011; Strauss et al., 2012). For example, the pushed by necessity group is most involved in considering seeking a job in employment, which is in line with the fact that they are pushed into solo self-employment and imagine their future work selves as an employee facing fewer risks. Additionally, we found the groups that are solo self-employed for more instrumental motives, such as the occupationally-driven solo self-employed and control-seekers, to be most engaged in proactive career behaviors. This suggests that the solo self-employed are encouraged to proactively manage their career also if being solo self-employed is not motivated by an intrinsic need. High engagement in proactive career behaviors of the occupationally-driven solo self-employed may however also be explained by the external requirements, in terms of for example skills and knowledge development, that have been established for some professional categories to regulate their members' professional 
standards and the practice of their work (Evetts, 2011). Hence, from this perspective, the occupationally-driven solo self-employed might be encouraged to proactively manage their career not only by their motive to stay solo self-employed and hence become their future work selves, but also by external requirements.

The most surprising result of our study is that, in spite of reporting an intrinsic need to become solo self-employed (Strauss et al., 2012), entrepreneurs by heart are found to be the least engaged in the proactive career behaviors that were examined in this study. At first sight, this seemed to be in contrast with our argument that individuals are more likely to engage in behaviors helping them to become their future work selves. This finding may raise the question whether entrepreneurs by heart might overestimate themselves and think that they can be self-sufficient in creating their own opportunities when it comes to managing their entrepreneurial careers (Forbes, 2005) as they, for example, have a low engagement in finding other people to learn from or investing in skills and knowledge development. From this perspective their low engagement is alarming, as it could put entrepreneurs by heart in a vulnerable position and prevent them from fulfilling their future work selves. Regarding the motivational profile of entrepreneurs by heart, one could describe their career choice of becoming solo self-employed as a pursuit of their calling (Hall and Chandler, 2005). Feeling overconfident and undermining the value of professional development outside the calling domain have been acknowledged as the dark side of calling, which might explain why the entrepreneurs by heart seem to be the least engaged in proactive career behaviors (Lysova et al., 2018). Although the entrepreneurs by heart do not seem to engage in proactive career behaviors particularly related to developing oneself or one's career, which was the focus of this study, the entrepreneurs by heart could perhaps invest their time and effort in classic proactive entrepreneurial behavior. For example, as the careers of solo self-employed workers are characterized by high levels of uncertainty and unpredictability (Jacobs et al., 2019), investing time and effort in developing innovative business ideas could be an effective proactive behavior to cope with the ongoing pressure to innovate and deal with competitors (Anderson et al., 2018; Kafaji, 2020).

\section{Limitations and future research}

This study has limitations that partly result from data availability. With our research design, we cannot exclude that the differences in proactive career behaviors may be explained by alternative factors, such as demographic differences. However, including demographic differences as control variables would result in a 1-step LCA, which poses several methodological and statistical issues (Bakk et al., 2013), as the configuration of the classes will always be affected by the control variables. Hence, the classes formed would represent not only the starting motives, but also the control variables. Future research should therefore examine whether demographic differences in the groups of solo self-employed, such as educational levels and occupations, explain differences in proactive career behaviors. Relatively high percentages of low education and low skilled occupations among the pushed by necessity may suggest that this group consists of vulnerable workers lacking the power to land their preferred job in employment as a result of the increased externalization of peripheral organizational tasks. Additionally, the age of the business might also provide an explanation for engagement in proactive career behaviors. It might be that the older the business, the less valuable it is to engage in proactive career behaviors, such as skills and knowledge development and networking, due to experience and existing networks. Future research is needed to investigate further demographic differences among the solo selfemployed and their role in explaining their proactive career behaviors.

Furthermore, to identify motivational profiles based on starting motives, LCA was applied to cross-sectional data drawn from the 2015 Dutch Self-employed Working Conditions
Motivational profiles and career behaviors 
CDI

26,2

326

Survey (conducted by CBS and TNO, Janssen et al., 2015). The Dutch Self-employed Working

Conditions Survey items are based on a pre-existing questionnaire including a list of 12 starting motives reflecting a wide range of starting motives. Although these starting motives were also used in previous studies (e.g., Dawson and Henley, 2012; Dirven et al., 2017), the presented starting motives might not be exhaustive. For example, as Hughes (2003, p. 449) identified in her qualitative study, "eroding working conditions, job stress and insecurity" might also partially push people to starting a business, which was not included in the preexisting questionnaire used in this study. Therefore, for future research on starting motives for the solo self-employed, it is recommended to use a qualitative exploratory approach to identify additional starting motives as well as understanding the mechanism of how combinations of specific starting motives might trigger engagement in proactive career behavior.

Finally, as this study was limited by examining a restricted number of proactive career behaviors due to the secondary data analysis, it might be relevant to examine other proactive career behaviors, such as showing career initiative, which refers to proactively planning and shaping one's career by, for instance, setting goals and formulating a plan to achieve the goals (Locke and Latham, 2006). By setting goals, the solo self-employed might become more aware of how to achieve these goals by engaging in other proactive career behaviors. With regard to engagement in networking behavior, we recommend for future research to examine whether the solo self-employed have other intentions to engage in this behavior besides seeking people to learn from, such as building strong relations with clients, which is important for obtaining new assignments (Engel et al., 2017).

\section{Practical implications}

In this study we used a person-centered approach, through which we identified six motivational profiles among the solo self-employed. Our results have a number of policy implications as they provide a classification system. This classification system found by using the person-centered approach allows policy makers to think in terms of groups of solo self-employed workers and develop corresponding interventions tailored to these different groups (Hofmans et al., 2020). For example, since the entrepreneurs by heart expressed a low level of engagement in the proactive career behaviors that were captured in the present study, we see opportunities for policy makers to create more general awareness about the value of engaging in proactive career behaviors among the solo self-employed, as literature has shown that engagement in proactiveness is positively related to achieving career goals (De Vos and Soens, 2008). With regard to the high engagement in seeking a job in employment of the pushed by necessity solo self-employed, qualitative research could help us explore what resources the pushed by necessity expect to attain in employment, which they potentially miss in solo self-employment. For example, if these solo self-employed workers consider a job in employment as a way to increase their levels of financial security (Burke et al., 2008), policymakers could use these insights to act upon the need for security of solo self-employed workers pushed by necessity.

\section{Conclusion}

The aim of this paper was to advance our understanding of the heterogeneity among solo selfemployed workers (Burke, 2015) using an innovative theoretical and methodological approach. By using a person-centered research method, we were able to explore a potentially more advanced configuration of starting motives compared to the push-pull dichotomy (Hofmans et al., 2020). We made an explorative but in-depth contribution to the literature about motivational profiles to become solo self-employed and their relationship with the 
engagement in proactive career behaviors. As groups of solo self-employed workers differed in terms of their motives for becoming solo self-employed, the push-pull approach was shown too variable-centered to represent the heterogeneity among solo self-employed. With more insight on the different motivational profiles, we encourage future scholars for a more indepth exploration within motivational profiles as well as cross-country comparison of these profiles. In addition, the solo self-employed differed in their engagement in proactive career behaviors and therefore seemed to have different strategies in managing their business, which might expose them to different degrees of risk. For future scholars, we recommend to explore the relation between engagement in proactive career behavior and entrepreneurial success. Hence, we have demonstrated the need for researchers to distinguish different groups of solo self-employed when identifying factors that may enhance their well-being and performance.

\section{Notes}

1. The conditional probabilities of saying "Yes" to each item (i.e., starting motive) show that groups of solo self-employed display quite distinct motivational profiles.

2. The cross-groups significant difference patterns show which motivational profiles significantly differ in their engagement in a proactive behavior. When motivation profile numbers are mentioned between brackets, this refers to a non-significant difference between this particular motivational profile and other profiles.

\section{References}

Akkermans, J. and Kubasch, S. (2017), "Trending topics in careers: a review and future research development", Career Development International, Vol. 22 No. 6, pp. 586-627.

Anderson, R.W., Acur, N. and Corney, J. (2018), "How do SMEs use open innovation when developing new business models", Researching Open Innovation in SMEs, pp. 179-209.

Appelbaum, E., Bailey, T., Berg, P. and Kalleberg, A.L. (2000), Manufacturing Advantage: Why Highperformance Work Systems Pay off, Cornell University Press, Ithaca.

Bakk, Z., Tekle, F.B. and Vermunt, J.K. (2013), "Estimating the association between latent class membership and external variables using biasadjusted three-step approaches", Sociological Methodology, Vol. 43 No. 1, pp. 272-311.

Barron, J.M., Berger, M.C. and Black, D.A. (1997), "How well do we measure training?", Journal of Labor Economics, Vol. 15 No. 3, pp. 507-528.

Blesa, A. and Ripollés, M. (2003), "The role of market orientation in the relationship between entrepreneurial proactiveness and performance", Journal of Entrepreneurship, Vol. 12 No. 1, pp. 1-19.

Bredvold, R. and Skålén, P. (2016), "Lifestyle entrepreneurs and their identity construction: a study of the tourism industry", Tourism Management, Vol. 56, pp. 96-105.

Burke, A.E. (Ed.) (2015), The Handbook of Research on Freelancing and Self-Employment, Senate Hall Academic Publishing, Dublin.

Burke, A.E., FitzRoy, F.R. and Nolan, M.A. (2008), "What makes a die-hard entrepreneur? Beyond the 'employee or entrepreneur' dichotomy”, Small Business Economics, Vol. 31 No. 2, pp. 93-115.

Carsrud, A. and Brännback, M. (2011), "Entrepreneurial motivations: what do we still need to know?", Journal of Small Business Management, Vol. 49 No. 1, pp. 9-26.

Chiaburu, D.S., Baker, V.L. and Piariu, A.H. (2006), "Beyong being proactive: what (else) matters for career self-management behaviors?”, Career Development International, Vol. 11 No. 7, pp. 619-632.
Motivational profiles and career behaviors 
CDI

26,2

328

Dawson, C. and Henley, A. (2012), “Push' versus 'pull' entrepreneurship: an ambiguous distinction?”, International Journal of Entrepreneurial Behavior and Research, Vol. 18 No. 6, pp. 697-719.

De Vos, A. and Soens, N. (2008), "Protean attitude and career success: the mediating role of self management", Journal of Vocational Behavior, Vol. 73 No. 3, pp. 449-456.

De Vos, A., Van der Heijden, B.I. and Akkermans, J. (2020), "Sustainable careers: towards a conceptual model”, Journal of Vocational Behavior, Vol. 117, doi: 10.1016/j.jvb.2018.06.011.

Dempster, A.P., Laird, N.M. and Rubin, D.B. (1977), "Maximum likelihood from incomplete data via the em algorithm", Journal of the Royal Statistical Society: Series B, Vol. 39 No. 1, pp. 1-38.

Dirven, H.J., van der Torre, W. and van den Bossche, S. (2017), "Een slechte start en dan? De werksituatie van zelfstandig ondernemers met negatieve en positieve startmotieven' [A bad start and then? The work situation of self-employed entrepreneurs with negative and positive starting motives.]", Tijdschrift Voor Arbeidsuraagstukken, Vol. 33 No. 3, pp. 286-302.

Engel, Y., Van Burg, J.C., Kleijn, E. and Khapova, S.N. (2017), "Past career in future thinking: how career management practices shape entrepreneurial decision-making", Strategic Entrepreneurship Journal, Vol. 11 No. 2, pp. 122-144.

Evetts, J. (2011), “A new professionalism? Challenges and opportunities”, Current Sociology, Vol. 59 No. 4 , pp. $406-422$.

Feldman, D.C. and Bolino, M.C. (2000), "Career patterns of the self-employed: career motivations and career outcomes”, Journal of Small Business Management, Vol. 38 No. 3, pp. 53-68.

Forbes, D.P. (2005), “Are some entrepreneurs more overconfident than others?", Journal of Business Venturing, Vol. 20, pp. 623-640.

Freese, C. and Van den Groenendaal, S.M.E. (2020), "Het ervaren en reduceren van onzekerheid door zzp'ers [Experiencing and reducing the insecurity by the solo self- employed]", Dynamiek op de Nederlandse Arbeidsmarkt: De Focus op Zekerheid [Dynamics in the Dutch Labour Market: The Focus on Security], CBS/TNO, pp. 147-174.

Halal, W.E. (2001), "The collaborative enterprise A stakeholder model uniting profitability and responsibility", The Journal of Corporate Citizenship, Vol. 2, pp. 27-42.

Hall, D.T. and Chandler, D.E. (2005), "Psychological success: when the career is calling", Journal of Organizational Behavior, Vol. 26 No. 2, pp. 155-176.

Hirschi, A., Freund, P.A. and Herrmann, A. (2014), "The career engagement scale: development and validation of a measure of proactive career behaviors", Journal of Career Assessment, Vol. 22 No. 4, pp. 575-594.

Hofmans, J., Wille, B. and Schreurs, B. (2020), "Person-centered methods in vocational research", Journal of Vocational Behavior, Vol. 118, doi: 10.1016/j.jvb.2020.103398.

Howard, J., Gagné, M., Morin, A.J. and Van den Broeck, A. (2016), "Motivation profiles at work: a self determination theory approach", Journal of Vocational Behavior, Vol. 95, pp. 74-89.

Hughes, K.D. (2003), "Pushed or pulled? Women's entry into self-employment and small business ownership", Gender, Work and Organization, Vol. 10 No. 4, pp. 433-454.

Jacobs, S., De Vos, A., Stuer, D. and Van der Heijden, B.I.J.M. (2019), "Knowing me, knowing you" the importance of networking for freelancers' careers: examining the mediating role of need for relatedness fulfillment and employability-enhancing competencies", Frontiers in Psychology, Vol. 10 No. 2055, pp. 1-14.

Janssen, B.J.M., Van der Torre, W., De Vroome, E.M.M., Mol, M., Janssen, B. and Van den Bossche, S.N.J. (2015), Zelfstandigen Enquête Arbeid 2015: Methodologie en globale resultaten [Dutch Self employed Working Conditions Survey: Methodology and global results], CBS/TNO, Heerlen/ Leiden.

Jayawarna, D., Rouse, J. and Kitching, J. (2011), "Entrepreneur motivations and life course", International Small Business Journal, Vol. 31 No. 1, pp. 34-56. 
Kafaji, M. (2020), "Delegation and collaboration practices to embrace innovative ideas for business growth in small to medium enterprises", International Journal of Entrepreneurship, Vol. 24 No. 1 , pp. 1-8.

King, Z. (2004), "Career self-management: its nature, causes and consequences”, Journal of Vocational Behavior, Vol. 65 No. 1, pp. 112-133.

Kirkwood, J. (2009), "Motivational factors in a push-pull theory of entrepreneurship", Gender in Management:An International Journal, Vol. 24 No. 5, pp. 346-364.

Kossek, E.E., Roberts, K., Fisher, S. and DeMarr, B. (1998), "Career self-management: a quasi experimental assessment of the effects of a training intervention”, Personnel Psychology, Vol. 51, pp. 935-962.

Locke, E.A. and Latham, G.P. (2006), "New directions in goal-setting theory", Current Directions in Psychological Science, Vol. 15 No. 5, pp. 265-268.

Lysova, E., Jansen, P.G.W., Khapova, S.N., Plomp, J. and Tims, M. (2018), "Examining calling as a double edged sword of employability", Journal of Vocational Behavior, Vol. 104, pp. 261-272.

Magni, F. and Mazzini, A. (2018), "Collaboration and entrepreneurship education: requirements and perspective", in Bosio, G., Minola, T., Origo, F. and Tomelleri, S. (Eds), Rethinking Entrepreneurial Human Capital the Role of Innovation and Collaboration, pp. 89-104, Springer International Publishing.

Murgia, A. and Pulignano, V. (2019), "Neither precarious nor entrepreneur: the subjective experience of hybrid self-employed workers", Economic and Industrial Democracy, pp. 1-27, doi: 10.1177/ $0143831 X 19873966$.

Neneh, B.N. (2019), "From entrepreneurial intentions to behavior: the role of anticipated regret and proactive personality", Journal of Vocational Behavior, Vol. 112, pp. 311-324.

Nylund, K.L., Asparouhov, T. and Muthén, B.O. (2007), "Deciding on the number of classes in latent class analysis and growth mixture modeling: a Monte Carlo simulation stud", Structural Equation Modeling: A Multidisciplinary Journal, Vol. 14 No. 4, pp. 535-569.

Pérez-López, M.C., González-López, M.J. and Rodríguez-Ariza, L. (2016), "Competencies for entrepreneurship as a career option in a challenging employment environment", Career Development International, Vol. 21 No. 3, pp. 214-229.

Plomp, J., Tims, M., Akkermans, J., Khapova, S.N., Jansen, P.G.W. and Bakker, A.B. (2016), “Career competencies and job crafting - how proactive employees influence their well being", Career Development International, Vol. 21 No. 6, pp. 587-602.

Ryan, R.M. and Deci, E.L. (2000), "Self-determination theory and the facilitation of intrinsic motivation, social development, and well-being", American Psychologist, Vol. 55 No. 1, pp. 68-78.

Schumpeter, J.A. (1934), The Theory of Economic Development, Harvard University Press, Cambridge.

Segal, G., Borgia, D. and Schoenfeld, J. (2005), "The motivation to become an entrepreneur", International Journal of Entrepreneurial Behavior and Research, Vol. 11 No. 1, pp. 42-57.

Sorgner, A. and Fritsch, M. (2013), "Occupational choice and self-employment-are they related?", SSRN Electronic Journal. doi: 10.2139/ssrn.2205034.

Spurk, D., Hirschi, A., Wang, M., Valero, D. and Kauffeld, S. (2020), "Latent profile analysis: a review and "how to" guide of its application within vocational behavior research", Journal of Vocational Behavior, Vol. 120, pp. 1-21, doi: 10.1016/j.jvb.2020.103445.

Strauss, K., Griffin, M.A. and Parker, S.K. (2012), "Future work selves: how salient hoped-for identities motivate proactive career behaviors", Journal of Applied Psychology, Vol. 97 No. 3, pp. 580-598.

Van der Heijden, B.I.J.M. and De Vos, A. (2015), "Sustainable careers: introductory chapter", in De Vos, A. and Van der Heijden, B.I.J.M. (Eds), Handbook of Research on Sustainable Careers, Edward Elgar Publishing, Cheltenham and Northampton, MA, pp. 1-19.

Van Gelderen, M. and Jansen, P. (2006), "Autonomy as a start-up motive”, Journal of Small Business and Enterprise Development, Vol. 13 No. 1, pp. 23-32.
Motivational profiles and career behaviors 
CDI 26,2

Van Stel, A. and De Vries, N. (2015), "The economic value of different types of solo self employed: a review", The Handbook of Research on Freelancing and Self-Employment, Senate Hall Academic Publishing, Dublin, pp. 77-84.

Vermunt, J.K. (2010), "Latent class modeling with covariates: two improved three-step approaches", Political Analysis, Vol. 18 No. 4, pp. 450-469.

Vermunt, J.K. and Magidson, J. (2013), Technical Guide for Latent GOLD 5.0: Basic, Advanced, and Syntax, Statistical Innovations, Belmont, Massachusetts.

Wennberg, K., Wiklund, J., DeTienne, D.R. and Cardon, M.S. (2010), "Reconceptualizing entrepreneurial exit: divergent exit routes and their drivers", Journal of Business Venturing, Vol. 25 No. 4, pp. 361-375.

Ybema, J.F., van der Torre, W., de Vroome, E., van den Bossche, S., Lautenbach, H., Banning, R. and Dirven, H. (2012), Zelfstandigen Enquête Arbeid 2012: Methodologie en beschrijvende resultaten [Dutch Self employed Working Conditions Survey: Methodology and descriptive results], CBS/ TNO, Heerlen/Leiden.

Zahra, S.A., Nielsen, A.P. and Bogner, W.C. (1999), "Corporate entrepreneurship, knowledge, and competence development", Entrepreneurship: Theory and Practice, Vol. 23 No. 3, pp. 169-189.

Zali, M.R., Faghih, N., Ghotbi, S. and Rajaie, S. (2013), "The effect of necessity and opportunity driven entrepreneurship on business growth", International Research Journal of Applied and Basic Sciences, Vol. 7 No. 2, pp. 100-108.

\section{Appendix}

The supplementary files are available online for this article.

\section{Corresponding author}

Sjanne Marie Elyse van den Groenendaal can be contacted at: s.m.e.vdngroenendaal@, tilburguniversity.edu

For instructions on how to order reprints of this article, please visit our website:

www.emeraldgrouppublishing.com/licensing/reprints.htm

Or contact us for further details: permissions@emeraldinsight.com 